\title{
FLEXIBLE AND TELESCOPIC VACUUM CHAMBERS FOR THE APS BUNCH COMPRESSOR*
}

\author{
D.R. Walters ${ }^{\dagger}$ and L.H. Morrison \\ Advanced Photon Source, Argonne National Laboratory, Argonne, IL
}

\begin{abstract}
The Advanced Photon Source (APS) bunch compressor was built with the goal of producing electron bunches with high peak current. Vacuum chamber liners were designed to reduce the interaction of the electron beam with the surrounding chamber walls. The goal was to have the field of the beam encountering chamber walls that are smooth having diametrical changes that are well controlled. This paper shows the design and construction of our special bellows chambers that are used in the chicane and straight sections of the beamline. The bunch compressor in the APS linac has movable magnets so that the aspect ratio and the compressor displacements are variable. To accommodate this, two types of special chambers are needed: a flexible chamber for different bending angles and a telescopic chamber for length changes in the beamline.
\end{abstract}

\section{INTRODUCTION}

The Advanced Photon Source (APS) is a facility for material science and biological research. It provides users with a source of x-rays at energy of $7 \mathrm{GeV}$. The main electron beam is contained within the storage ring that is two-thirds of a mile in circumference. The storage ring is divided into 40 sectors with isolation valves between each sector. An experimental free-electron laser has been constructed at the APS driven by the electron linac to produce light using the self-amplified spontaneous emission process [1]. In order to improve the photocathode gun electron beam, a bunch compressor has been constructed within the linac. This apparatus has decreased the length of the electron beam pulse and increased the peak current by a factor of $\sim 7$ [2]. An additional feature being implemented to this bunch compressor is the ability to move the bending magnets to change the degree of beam compression.

The function of both types of beam chamber liners shown in this report is to reduce the effect of the wall wakefields when the electron beam travels through the chambers. The wakefield is imaged on the chamber walls and feeds back to the beam that caused it, reducing the intensity of the wakefields.

\section{BENDING MAGNET CHAMBERS}

The " $\mathrm{H}$ " style dipole magnets used for the chicane have apertures of $40 \mathrm{~mm}$ in the center axis of the beamline.

*Work supported by the U.S. Department of Energy, Office of Basic Energy Sciences under contract No. W-31-109-ENG-38.

†drw@aps.anl.gov
This limits the clearance for the beam going through a bellows with a liner. The liner is a dual-pivot parallelplate type design mounted inside a racetrack-shaped copper bellows. The plates are $26.9 \mathrm{~mm}$ wide with a gap of $14.78 \mathrm{~mm}$. Because the gap is $55 \%$ of the width, it is believed that the wakefield will be largely controlled by the gap rather than the width. When the bunch compressor is set up with the maximum aspect ratio, 2:1, the angle that the beam is bent is 13.4 degrees.

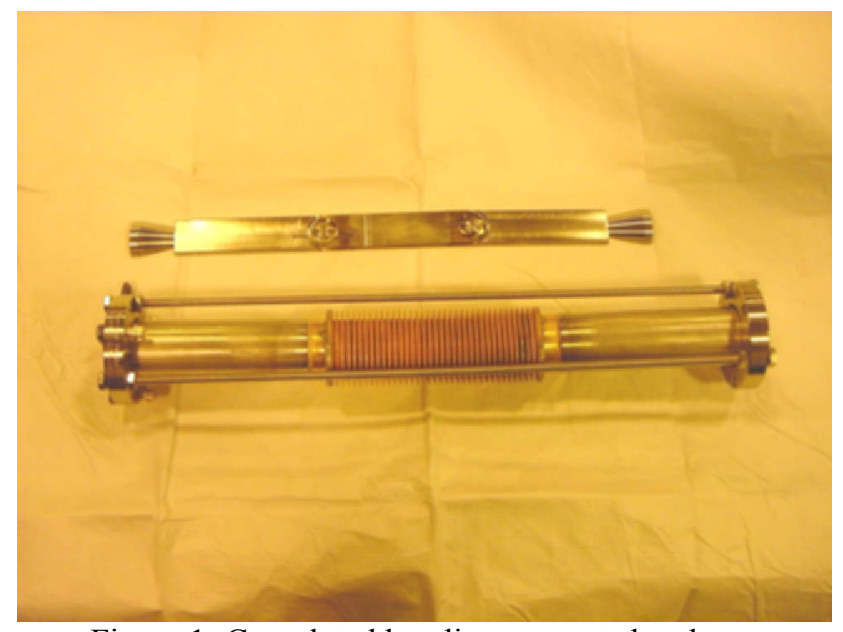

Figure 1: Completed bending magnet chambers.

The two major parts of this assembly are the vacuum chamber shell and the chamber liner. The shell, shown in Fig. 1, uses standard metal sealed flanges and an electroformed copper bellows. The bellows is $50.8 \mathrm{~mm}$ wide and $38.1 \mathrm{~mm}$ high and is made by electrodepositing high-purity copper onto a disposable mandrel. The result is a bellows that is leak-tight, flexible, and it has a shape other than circular. A factor to be considered when using a bellows of this type is the low service temperature.

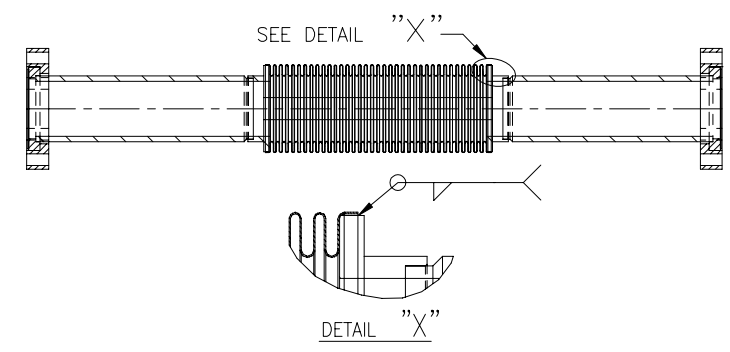

Figure 2: Detail of solder joint.

The highest continuous temperature that the bellows can take is $200^{\circ} \mathrm{F}$. For short periods this temperature can be increased to allow joining. In this case the joining 
technique was soldering. A new type of lead-free solder, $93.6 \% \mathrm{Sn} / 4.7 \% \mathrm{Ag} / 1.7 \% \mathrm{Cu}$, was chosen. It has a low melting point and the ingredients are all known to be compatible with high vacuum. To accommodate this solder, the assembly was made so that the joint would be a copper-to-copper connection (see Fig. 2). The flux used on the joint is water-soluble and was cleaned using a cleaning regiment of Citrox/ultrasonics and hot deionized water. Two test pieces were made: one with both the solder and the flux on it (no cleaning), and one with solder/flux but cleaned and baked $\left(100{ }^{\circ} \mathrm{C}\right)$ to see whether the flux penetrated the pores of the solder. The samples were examined to check for any residue using x-ray photoelectron spectroscopy. The result of these tests shows that the cleaning did remove the flux and that even with the baking there was no detectable flux residue.

The chamber liner consists of two parallel plates welded onto the inner walls of the stainless steel extension tubes.

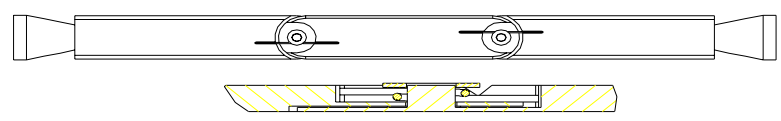

Figure 3: Detail of plate assembly.

The plate assemblies, shown in Fig. 3, are made up of two endpieces and a center link. The parts are connected by two pin joints on either end of the center link. The pin in the rotary joint is integral to the endpiece, as is the transition cone, which allows for a smoother blend from the flat plate to the inside of the tube. Within each rotary joint is a torsional spring used to return the endpieces and the center link into a straight line. The pieces are coated with a thin film of titanium nitride to prevent the stainless steel from seizing together.

\section{TELESCOPING BELLOWS}

Circular bellows are included in the beamline to accommodate the displacement of the magnets. Owing to degradation of the electron beam by wakefields, a telescopic liner is included to smooth the walls that the wakefield travels along. In this installation there are two types of bellows with telescopic liner: the 498-mm stroke five-segment telescope, and the 20.3-mm stroke twosegment telescope. The details given in the following description of the five-segment telescope also apply to the two-segment telescope. Five interlocking tubes make up the liner and four of the segments have an outside groove for securing a retaining ring. The rings function as a stop when the telescope is collapsed. When it is expanded there are integral steps that interlock one segment to the next. The steps are contoured (see Fig. 4) on the ends to allow a large cone of misalignment from one segment to the next.

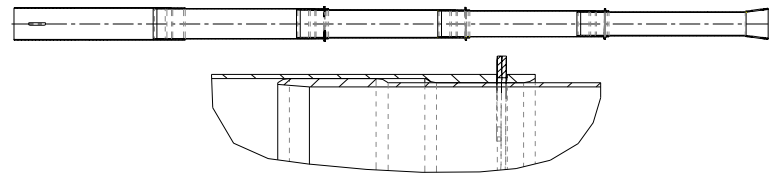

Figure 4: Detail of interlocking liner segments.

The function of the contour is to present a rounded corner to the inside wall of the next larger interlocked segment. Without the radius the corner would be sharp and would dig into the wall and seize. After machining, the inside and outside surfaces are mechanically polished to a 12-micro-inches finish. They are then electropolished to a finish of 6 micro-inches. The final step is to apply a chromium-type coating, furnished by the Armoloy ${ }^{\circledR}$ Company. The designation of this coating is XADC Armoloy ${ }^{\circledR}$ and is documented to have a low coefficient of friction in vacuum conditions. In that there was an earlier design that failed our in-house 500-cycle test, this design evolved with an improvement of surface finish, radiused corners, and a coating known for its low coefficient of friction in vacuum. This assembly, shown in Fig. 5, is then welded into a 316L stainless steel bellows that is terminated with metal-sealed flanges.

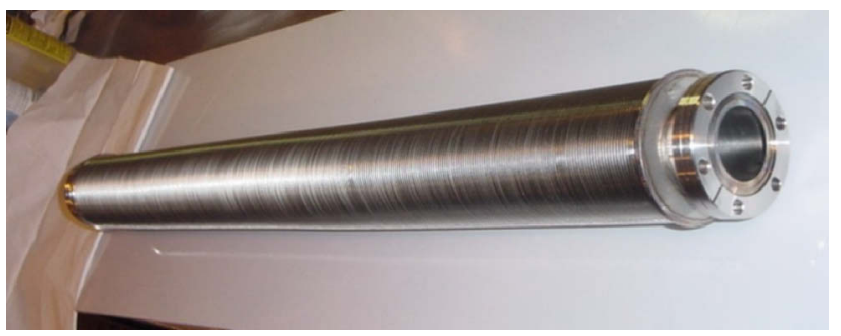

Figure 5: Completed telescoping bellows chamber.

\section{PREINSTALLATION TESTING}

The apparatus for testing the bending-magnet chambers is shown in Fig. 6. The test was performed by using a pneumatic cylinder to bend the chamber from an in-line position to an angle of 15 degrees.

Each chamber was successfully tested to 500 cycles before it was installed in the APS linac. Fig. 7 shows the apparatus used to test the telescoping bellows chambers. A ball screw is employed to move the chamber end for the $500 \mathrm{~mm}$ of travel. The switches attached to the moving end are used to signal the controller to reverse the motor direction. The telescopic chambers were also tested to 250 cycles. All chambers were tested under vacuum conditions in which the pressure was lower than $3 \times 10^{-6}$ Torr. 


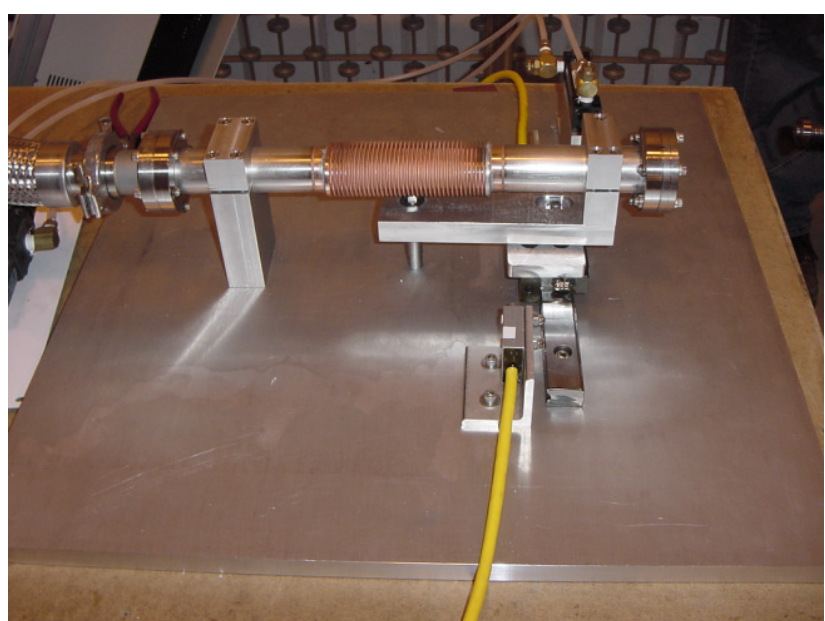

Figure 6: Test-fixture for bending magnet chamber

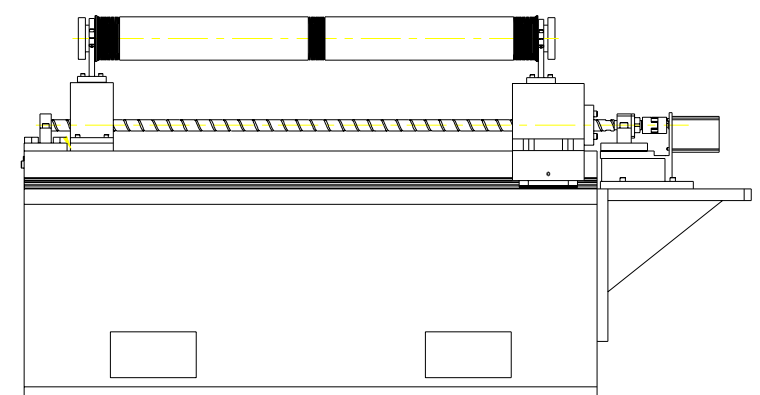

Figure 7: Test-fixture for telescoping bellows chamber.

\section{CONCLUSIONS}

The rotary joints in the bending-magnet chambers used titanium nitride to prevent seizure and Armoly ${ }^{\circledR}$ XADC coating as a solid lubricant in the sliding joints in the bellow liner. These materials were selected for their application compatibility and availability. Other choices for solid lubricants appear promising but were not tried at this point. Examples of other considerations for this film lubricant are Dicronite, diamond-like-coatings, and molydisulfide/gold coatings. The molydisulfide/gold coating has some advantages and will be evaluated in the near future for use in the APS linac. The true test of the parts will be in using them in the variable bunch compressor. As of this writing those tests have not been run. Data will be reported in the future after the parts are installed and the tests are run.

\section{ACKNOWLEDGMENTS}

The authors are indebted to George Fenske, Robert Erck, John Woodford, Oyelayo Ajayi, and Jeff Hershberger of the Tribology Section for their help and suggestions; to William Toter for soldering and brazing advice; to Steve Berg for advice on brazing and the brazing materials; to Charles Doose for testing the magnetic properties of the Armoloy ${ }^{\circledR}$ coating; to Richard Rosenberg for evaluating the composition of the solder and flux; to Dan Vanlannen and Robin Reierson for their skills in welding and soldering; to Joe Gagliano for making the controls and programming the PLC; and to Aaron Lopez, Mark Martens, and Wayne Michalek for testing the chamber assemblies.

\section{REFERENCES}

[1] S.V. Milton et al., "The APS SASE FEL: Status and Commissioning Results," Proceedings of the 1999 Particle Accelerator Conference, New York (1999).

[2] M. Borland et al., "Initial Characterization of Coherent Synchrotron Radiation Effects in the APS Bunch Compressor," these proceedings (2001). 